\title{
Late complication of heart stimulation - lead abrasion in pacemaker pocket
}

\author{
Odległe powikłanie stymulacji serca - przetarcie elektrod w loży urządzenia
}

\author{
Krzysztof Boczar $^{1}$, Barbara Małecka ${ }^{1,2}$, Andrzej Ząbek ${ }^{1}$, Kazimierz Haberka ${ }^{1}$, Jacek Lelakowski ${ }^{1,2}$ \\ 'Department of Electrocardiology, John Paul II Hospital in Krakow, Poland \\ 2Institute of Cardiology, Jagiellonian University Medical College in Krakow, Poland
}

An 81-year-old male patient was hospitalised due to recurrence of syncope 4 years after DDD pacemaker (PM) implantation. The DDD pacing system contained Vitatron C60DR PM and 2 Vitatron Crystalline BP leads: an atrial one implanted by left subclavian venipuncture, and a ventricular one implanted by left cephalic venesection. In this PM-dependent patient, periodic inhibition of pacing up to $2 \mathrm{~s}$ was recorded in Holter electrocardiogram. Pacing inhibition occurred although bipolar sensing was programmed. In the PM check-up, moving of the patient's left upper limb induced in intracardiac electrogram records (IEGM), short-cycle abnormal signals, so called 'crackles', simultaneously in atrial and ventricular channels (Fig. 1). The remaining parameters i.e. pacing thresholds and lead impedance, were correct. Lead damage was diagnosed and a decision to perform transvenous lead extraction (TLE) was made. Because this patient had left ventricular ejection fraction lowered to $30 \%$ in the course of ischaemic cardiomyopathy, we decided to perform simultaneous implantation of a new implantable cardioverter-defibrillator (ICD) to prevent sudden cardiac death. Before the TLE procedure, venography of left-side venous inflow was performed and occlusion of left brachiocephalic vein with advanced collateral circulation was observed (Fig. 2). Nevertheless, a $150 \mathrm{~cm}$-long guidewire Cordis 0.035 was successfully introduced into the heart. Firstly an ICD lead was implanted with the help of a set containing a long Peel-Away Curved Sheath made by Coock, designed for such a condition of blood vessels. The presence of the ICD lead in the right ventricle was used for temporary pacing during the removal of the damaged leads. Both leads were extracted using simple traction. Then we went along the narrowing of the inflow vein once again using a Medtronic Attain Command set designed for left ventricular lead implantation, and we implanted a new atrial lead. On examination of the extracted leads, we observed the presence of some abrasion in the external silicone lead insulation, with lead unsealing and metal wire exposure (Fig. 3). The damage distance from the distal end of the leads was compared to a chest X-ray conducted before TLE (Fig. 4). Measurements were performed using the DICOM system. This allowed the identification of sites of damage of the leads in the PM pocket where lead loops were located near the PM can, and where they remained in mutual

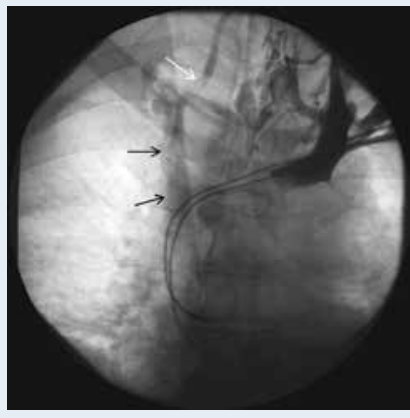

Figure 2. Collateral circulation with the inflow by right brachiocephalic vein (arrows)

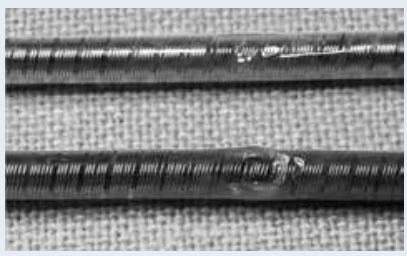

Figure 3. Silicone insulation breakage in macrophotography contact (Fig. 4). Abrasion of endocardial silicone leads due to mutual friction is an important clinical problem. In this process, silicone insulation gradually becomes thinner until it completely breaks. This can have a negative influence on the functioning of the pacing system. It seems justified to take into account the abrasion of lead insulation in cases of pacing inhibition in the presence of bipolar sensing leads.

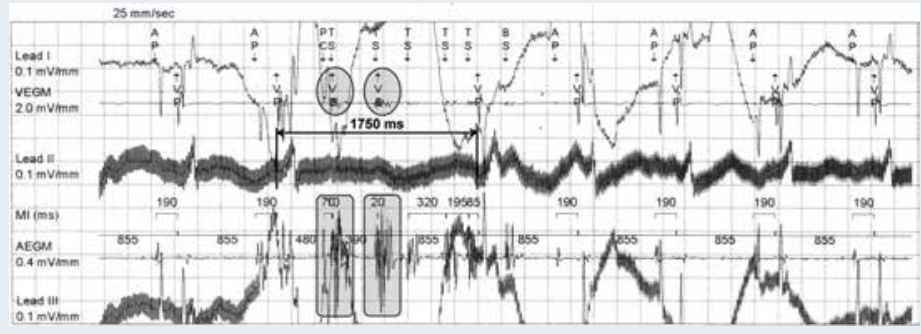

Figure 1. 'Crackles' in ventricular IEGM = VEGM (circles) and in atrial $\mathrm{IEGM}=\mathrm{AEGM}$ (rectangles), inhibiting pacing for $1750 \mathrm{~ms}$ with lack of rhythm - lead II (arrow). Artifacts in leads I and III - wandering of isoelectric line while moving left upper limb

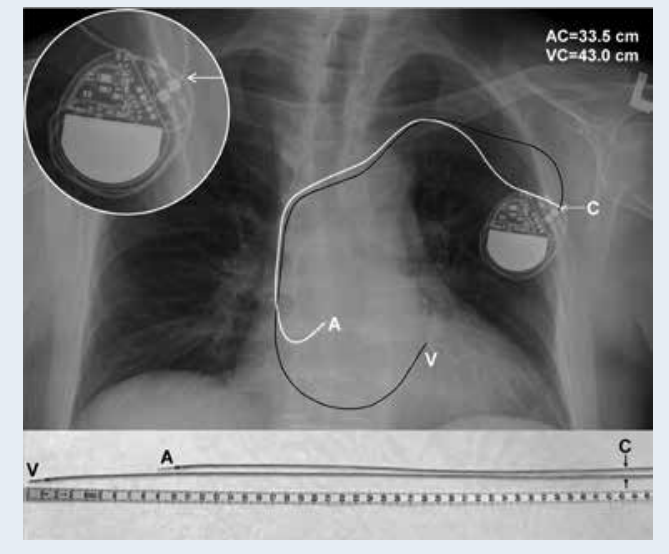

Figure 4. Chest $X$-ray - postero-anterior projection; A - atrial lead; $V$ - ventricular lead; $C$ - the site of mutual contact of leads in the pocket. In the circle can be seen magnification of the site $C$

Address for correspondence:

Andrzej Ząbek, MD, MSc, Department of Electrocardiology, John Paul II Hospital in Krakow, ul. Prądnicka 80, 31-202 Kraków, Poland, e-mail: andrzej___z@poczta.onet.pl

Conflict of interest: none declared 